\title{
Habilidades metatextuais e escrita de textos em alunos do Ensino Fundamental
}

\author{
Gislaine Gasparin Nobile ${ }^{1}{ }^{1}$ \\ Sylvia Domingos Barrera ${ }^{1}{ }^{1}$ \\ ${ }^{1}$ Universidade de São Paulo. São Paulo, SP, Brasil.
}

\section{Resumo}

A escrita de textos é uma habilidade complexa, que se apoia em competências cognitivas, linguísticas e metalinguísticas, como a habilidade metatextual, que envolve o conhecimento e controle sobre a estrutura dos diversos tipos de texto. O objetivo deste estudo foi analisar a relação entre a habilidade metatextual e o desempenho na produção escrita de histórias de alunos do Ensino Fundamental. Participaram da pesquisa 95 alunos do 4o e $5^{\circ}$ ano de uma escola pública, solicitados a escrever uma história com temática livre e a responder um questionário avaliando seu conhecimento sobre a estrutura narrativa de histórias. Os resultados indicaram correlação positiva entre a habilidade metatextual e a produção escrita. Os alunos do $5 \underline{0}$ ano apresentaram desempenho superior aos do 40 na produção de texto, mas não com relação à habilidade metatextual. Sugere-se, portanto, que essa seja objeto de desenvolvimento explícito pela escola, a fim de melhorar a qualidade dos textos produzidos.

Palavras-chave: escrita, habilidades metatextuais, metacognição.

\section{Metatextual abilities and writing of texts in elementary school students}

\begin{abstract}
Text writing is a complex skill that relies on cognitive, linguistic and metalinguistic skills, such as the metatextual ability that involves knowledge and control over the structure of the various types of text. The purpose of this study was to analyze the relationship between metatextual ability and the performance in the written production of stories of primary school students. A total of 95 students from the $4^{\text {th }}$ and $5^{\text {th }}$ degree of a public school were asked to produce a story about a free theme and to answer a questionnaire evaluating their knowledge about the narrative structure of stories. The results indicated a positive correlation between metatextual ability and written production. Fifth-grade students performed better than $4^{\text {th }}$-grade students in text production, but not in metatextual ability. It is suggested that this ability can be explicitly developed by the school in order to improve the quality of the texts produced.
\end{abstract}

Keywords: writing, metatextual skills, metacognition.

\section{Habilidades metatextuales y escrita de textos en estudiantes de escuela primaria}

\section{Resumen}

La escritura de textos es una habilidad compleja, que se apoya en competencias cognitivas, lingüísticas y metalinguísticas, como la habilidad metatextual que involucra el conocimiento y control sobre la estructura de los tipos de texto. El objetivo de este estudio fue analizar la relación entre habilidad metatextual y desempeño en la producción escrita de historias de alumnos de la Enseñanza Fundamental. Participaron de la investigación 95 alumnos del 4ㅇ y 5 año de una escuela pública, solicitados a producir una historia con temática libre y responder un cuestionario evaluando su conocimiento sobre estructura narrativa. Los resultados indicaron una correlación positiva entre habilidad metatextual y producción escrita. Los alumnos del 5 o año presentaron desempeño superior a los del 4 o en la producción de texto, pero no con relación la habilidade metatextual. Se sugiere que esta sea objeto de desarrollo explícito por la escuela a fin de mejorar la calidad de los textos producidos.

Palabras clave: escritura, habilidades metatextuales, metacognición. 
A produção escrita de textos é uma habilidade complexa, que se apoia em várias competências cognitivas, linguísticas e metalinguísticas, sendo a mais básica delas o domínio do sistema alfabético e de suas convenções ortográficas. Essa competência, entretanto, embora necessária, não garante por si só a escrita de textos. Assim, partindo do pressuposto de um grau de domínio razoável dessa competência básica, a maioria dos estudos desenvolvidos sobre o tema a partir de 1970, na abordagem cognitiva, têm em comum a descrição da produção do texto escrito como um processo que comporta três etapas: planejamento, formulação/transcrição e revisão (Flower \& Hayes, 1981; Foulin \& Mouchon, 2000).

O planejamento envolve uma reflexão sobre os objetivos do texto a ser escrito em termos de conteúdo (tema), forma (tipo de texto) e intenção comunicativa (para que, para quem). Do ponto de vista cognitivo, corresponde à recuperação e organização de informações (ou conhecimentos) na memória de longo prazo. Dessa forma, quanto maior o conhecimento do autor a respeito do tema sobre o qual deverá escrever, bem como sobre a estrutura do tipo de texto a ser escrito, mais rico e menos custoso será o processo de produção do texto. O planejamento do texto é a fase mais complexa na elaboração de um texto e, geralmente, os escritores inexperientes não conseguem realizar satisfatoriamente todas as tarefas cognitivas envolvidas (Foulin \& Mouchon, 2000).

No que se refere às peculiaridades dos vários tipos de texto, Marcuschi (2002) distingue tipo textual de gênero textual, sendo que o primeiro abrange as categorias básicas da narração, argumentação, exposição, descrição e injunção. Já o gênero, diz respeito à forma pela qual determinado tipo de texto se materializa, podendo consistir em um bilhete, bula de remédio, notícia de jornal, carta, história, etc.

A segunda etapa da produção escrita de textos envolve dois processos. O primeiro, formulação, diz respeito à transformação das ideias em unidades linguísticas, envolvendo a construção das frases e a coordenação dos enunciados sucessivos. Já a transcrição diz respeito à passagem das unidades linguísticas para as unidades gráficas, envolvendo a gestão da ortografia. Essa atividade motora de escrita, geralmente automatizada no escritor adulto, exige maior esforço físico e atenção consciente no escritor iniciante (Foulin \& Mouchon, 2000).

Por fim, a revisão corresponde a um processo de monitoramento e controle, cuja função é avaliar a qualidade (Spinillo \& Correa, 2016) e, caso necessário, modificar o texto produzido. Pode ocorrer tanto durante o curso da produção escrita, quanto ao final do processo de produção do texto. Estudos demonstram que os escritores novatos tendem a revisar os textos apenas quando finalizados e a centrarem sua revisão em aspectos ortográficos (Abaurre, 1997). Já os escritores proficientes analisam também a congruência entre as intenções enunciativas e o conteúdo do texto (Foulin \& Mouchon, 2000). Estudos têm evidenciado também que, enquanto os escritores iniciantes concentram suas energias cognitivas no processo de transcrição, nos escritores experientes essas energias são distribuídas de forma mais equilibrada entre todos os processos (planejamento, transcrição e revisão), os quais ocorrem também de forma mais interativa do que na escrita dos iniciantes, na qual predomina um processamento sequencial (Pereira \& Barbeiro, 2010).

O planejamento e controle envolvidos no processo de produção de textos nos permite analisá-lo a partir de um conceito bastante estudado pela Psicologia Cognitiva, sobretudo em suas interações com a aprendizagem escolar, o conceito de metacognição. $\mathrm{O}$ termo metacognição foi introduzido na Psicologia por Flavell, no final da década de 1970, para se referir à cognição sobre a cognição, envolvendo qualquer tipo de monitoramento ou atividade autorregulatória sobre o próprio comportamento cognitivo (Flavell, 1987).

De acordo com Brown (1987), desde a criação do termo metacognição, sua definição tem sido conturbada, por se tratar de um conceito complexo, sendo necessário fazer a distinção entre as duas dimensões envolvidas no uso do termo metacognição. De fato, este engloba, por um lado, os conhecimentos sobre os próprios conhecimentos, recursos e estratégias cognitivas mais eficientes para a realização de uma determinada atividade e, por outro, o controle e autorregulação na execução dessa atividade, processo esse que envolve a monitoração e avaliação dos resultados. Neste sentido, enquanto o conhecimento é estável e passível de verbalização, o controle é mais instável e nem sempre passível de verbalização (Corso, Sperb, Jou, \& Salles, 2013).

Mesmo diante dessas questões, alguns estudos apontam que é incontestável o papel da metacognição como meio de potencializar a aprendizagem. De fato, o conhecimento metacognitivo do aprendiz, tanto sobre fatores externos como internos que afetam o seu desempenho e a sua aprendizagem, possibilitam a utilização desse mesmo conhecimento na busca de um melhor resultado (Jou \& Sperb, 2006; Ribeiro, 2003). Assim, Paris, Lispson e Wixson (1983), distinguem três tipos de conhecimentos: (a) declarativo, referente ao conhecimento sobre o que se sabe; (b) processual, relativo aos procedimentos de como aplicar uma estratégia e, (c) condicional, conhecimento de quando, 
onde e por que aplicar uma estratégia específica. Inicialmente, o aprendiz desenvolve o conhecimento declarativo e, posteriormente os demais, processual e condicional, os quais possibilitam maior grau de controle e autorregulação.

As crianças mais novas não sabem interpretar suas experiências cognitivas (Jou \& Sperb, 2006), sendo que é por meio do desenvolvimento cognitivo e da sua participação em situações instrucionais, sobretudo as escolares, que surgem novas operações cognitivas, contribuindo assim para a conscientização do significado das experiências e dos processos cognitivos, suas implicações e como utilizá-las. Um dos processos cognitivos do qual as crianças aos poucos se apropriam conscientemente, é a linguagem, podendo-se considerar o desenvolvimento das habilidades metalinguísticas como um aspecto importante da metacognição (Gombert, 1992; Hodges \& Nobre, 2012).

Maluf e Gombert (2008) utilizam o termo "habilidades metalinguísticas", para se referirem ao controle consciente sobre os aspectos formais da linguagem oral a serem manipulados intencionalmente. De acordo com Gombert (1992; 2003), as primeiras habilidades que a criança manifesta são de ordem epilinguística (conhecimentos linguísticos implícitos, adquiridos espontaneamente); com a escolarização formal esses conhecimentos evoluem e, por meio do ensino intencional, a criança passa a lidar de forma mais consciente com a linguagem, desenvolvendo as habilidades metalinguísticas. Essas, por sua vez, podem se referir a diferentes aspectos da linguagem oral, como é o caso das chamadas habilidades metafonológicas, metassintáticas, metamorfológicas e metatextuais.

O termo habilidade metatextual, introduzido por Gombert na década de 1990, se refere a um tipo de habilidade metalinguística que possui como objeto de análise e reflexão o texto - considerando seus marcadores e convenções, estrutura, partes constituintes - e o domínio da coesão e coerência (Gombert, 1992).

Assim como ocorre no desenvolvimento das outras habilidades metalinguísticas, incialmente a criança apresenta um conhecimento epilinguístico (não intencional, inconsciente) em relação ao texto (Gombert, 1992). Com o início da instrução formal, marcada pela entrada dessa criança na escola, espera-se que sua capacidade de análise e reflexão sobre o texto aumente, reconhecendo sua estrutura e organização, diferenciando entre os diversos tipos textuais, como também, produza textos (orais e escritos) estruturalmente bem elaborados.

Dentre as habilidades metalinguísticas, as habilidades metatextuais são as menos investigadas, pelo menos no que se refere aos estudos brasileiros.
Uma revisão sistemática, realizada por Silva e Guimarães (2017), nos bancos de dados Portal CAPES e Google Acadêmico, de estudos que pesquisaram essa habilidade e foram publicados entre os anos 2006 e 2016, encontrou 22 estudos científicos (12 artigos, 3 teses e 7 dissertações). Desses, quatro estudos investigaram as relações entre habilidades metatextuais e compreensão de textos, treze focaram o desenvolvimento das habilidades metatextuais na produção textual, dois envolveram a produção oral e três envolveram mais de uma habilidade linguística.

De forma geral, a revisão dos estudos aponta que a consciência da estrutura organizativa dos textos como também o monitoramento intencional da coesão e coerência são habilidades metatextuais que pode contribuir para a qualidade dos textos produzidos por escrito ou oralmente. Dentre os estudos analisados, predominou a análise dos elementos macrolinguísticos (estrutura) e, quanto aos gêneros textuais, a história. A maioria dos estudos analisou as habilidades metatextuais em atividades que envolveram a produção de textos escritos, sendo que alguns estudos de intervenção verificaram que o melhor desempenho na produção textual ocorreu após o ensino explícito que envolveu a reflexão sobre a coerência e coesão e/ou estrutura textual (Zaboroski et al., 2015; Pinheiro, 2012; Oliveira et al., 2014).

Como apontado na revisão sistemática, além da habilidade metatextual ser a menos investigada dentre as habilidades metalinguísticas, há bem poucos estudos que envolvem, ao mesmo tempo, competências de leitura e escrita, como na pesquisa de Lopes (2016) que incluiu a compreensão leitora e o resumo de narrativa. $\mathrm{O}$ estudo foi realizado com 57 alunos, de $5^{\circ}$ e $6^{\circ}$ ano do ensino fundamental, de escolas públicas. Foram aplicados testes de escolha simples para verificar as habilidades de compreensão e metatextuais, sendo que o resumo foi avaliado por meio de um quadro de referência contemplando as categorias e eventos principais e estrutura narrativa. Os resultados indicaram que houve correlação positiva moderada entre as habilidades metatextuais, tanto com a compreensão leitora, quanto com a escrita de resumos de textos narrativos.

Já o estudo de Pereira (2010), considerou as relações entre produção textual, compreensão e habilidade metatextual. Os 64 alunos participantes, de sete a nove anos, foram divididos em três grupos de acordo com a idade e a escolaridade, sendo submetidos, individualmente, a três tarefas: produção textual oral com tema dado; compreensão de texto (após a leitura de uma história, o aluno respondia a seis questões de natureza inferencial) e tarefa de habilidade 
metatextual (após a leitura de doze textos estímulos, o aluno era solicitado a dizer se o texto estava completo ou incompleto, justificando a resposta dada). Os resultados indicaram uma correlação positiva entre as três habilidades, porém o delineamento correlacional do estudo não possibilitou a análise da influência causal da habilidade metatextual sobre a produção e compreensão textual.

Ressalta-se que outros aspectos, além das habilidades metatextuais, têm se mostrado relacionados à produção de texto, como a idade, escolaridade, experiências prévias com textos e competências ortográficas do escritor (Lins e Silva \& Spinillo, 1998; Nobile \& Barrera, 2016; Pessoa, Correa, \& Spinillo, 2010; Salles \& Correa, 2014). Além disso, a influência das condições de produção textual também tem sido estudada. Nesse sentido, resultados indicam que escritores novatos parecem se beneficiar de um apoio linguístico ou pictórico na produção escrita de textos narrativos (Lins e Silva \& Spinillo, 2000; Pessoa, Correa, \& Spinillo, 2010; Nobile \& Barrera, 2016), sobretudo quando tais estímulos (ou mesmo o próprio tema) apresentam, de forma explícita, um conflito ou situação-problema (Santos \& Barrera, 2015; Barrera \& Santos, 2016).

Como já identificado pela pesquisa de Silva e Guimarães (2017), o tipo de texto mais trabalhado, também nas escolas e principalmente no Ensino Fundamental, é o texto narrativo através do gênero "história". Esse gênero textual, além de familiar às crianças de um modo geral, apresenta uma estrutura bem delimitada, sendo possível identificar o início (cena e personagens), o desenvolvimento (trama ou situação problema) e o final (desfecho e resolução da trama). De acordo com Spinillo e Martins (1997), quando o narrador não articula essas partes adequadamente, sua produção será menos coerente, envolvendo problemas relacionados à manutenção dos personagens durante a narrativa, à relação entre os eventos narrados e/ou à relação causal entre os eventos desenvolvidos na história e seu desfecho.

Por meio da delimitação dos componentes estruturais que compõem um texto narrativo, alguns estudos usam um sistema de análise com intuito de classificar os textos produzidos de acordo com a presença e o grau de elaboração desses componentes em uma produção textual. Um desses estudos, pioneiro no Brasil, foi o de Rego (1986). Realizado com 70 crianças da primeira série do Ensino Fundamental, era solicitado que cada uma escrevesse uma história. Foi observado que metade dos textos produzidos não apresentavam as características estruturais de histórias. A outra metade foi classificada em quatro níveis: nível 1, produção somente contendo a introdução; nível 2, introdução mais o relato de um evento principal; nível 3, acrescenta-se às partes citadas nos outros níveis um desfecho da história e nível 4, história completa. A partir desta categorização, outros estudos a utilizaram, replicando, ampliando e até mesmo criando novos níveis, como os de Ferreira e Spinillo (2003), Ferreira e Correa (2008), Nobile e Barrera (2016).

Há também estudos que analisaram outro tipo textual, como o de Pinheiro e Leitão (2007), realizado com o objetivo de verificar em que medida a consciência da estrutura prototípica do texto argumentativo se relacionaria com a utilização dessa estrutura em textos produzidos por 60 participantes ( 20 da $2^{\underline{a}}$ série; 20 da $5^{\text {a }}$ série e 20 do primeiro ano de cursos universitários) de instituições particulares de ensino. Os resultados do estudo indicaram que o mero conhecimento da estrutura argumentativa não se manifesta, necessariamente, na produção de textos argumentativos que utilizem essa estrutura adequadamente.

Percebe-se, pela análise da literatura, que o tema das habilidades metatextuais e sua relação com a produção escrita de textos, é relativamente novo e ainda pouco contemplado no contexto nacional. Além das questões teóricas, considera-se também o tema bastante relevante pela sua potencial contribuição para o aprimoramento das práticas pedagógicas visando ao ensino da produção de textos. Nesse sentido, a presente pesquisa teve como objetivo geral analisar a relação entre as habilidades metatextuais, expressas pelo conhecimento sobre a estrutura de textos narrativos, e o desempenho na produção escrita de histórias, em alunos do Ensino Fundamental. Como objetivo específico, buscou-se comparar as habilidades metalinguísticas e o desempenho na produção de textos narrativos de alunos do 4 e 5 anos do Ensino Fundamental.

\section{Método}

A pesquisa efetuada, de caráter descritivo, seguiu o delineamento correlacional transversal, e foi realizada em escola pública escolhida por conveniência, localizada em cidade do interior paulista. Foram seguidos os protocolos éticos que regem os estudos com seres humanos, tendo sido obtido parecer favorável do Comitê de Ética da instituição à qual pertencem as pesquisadoras (protocolo no 26634914.0.0000.5407).

\section{Participantes}

Participaram do estudo 95 crianças, de ambos os sexos, alunos de 4o e 5ㅇano do Ensino Fundamental, idade média de 9,8 anos e desvio-padrão de 0,9. 
Destes, 35 (37\%) eram do 4⿳⺈ ano e 60 (63\%) do 5a ano. Todas as crianças autorizadas pelos pais/responsáveis participaram da pesquisa, porém alguns protocolos foram excluídos da análise dos dados por apresentarem textos ilegíveis, sobretudo no caso de alunos do $4^{\underline{O}}$ ano. Tal fato, aliado à possibilidade de reprovação de alunos ao final do $5^{\mathrm{O}}$ ano, justifica o maior número de participantes desse ano escolar.

\section{Material/instrumentos}

O material consistiu em folha de papel sulfite pautada para a produção de texto e um questionário, elaborado pelas pesquisadoras, para avaliar os conhecimentos dos participantes a respeito do gênero "história", Tal instrumento, denominado Questionário de Avaliação de Habilidades Metatextuais-História (QAHM-H), foi elaborado com base no instrumento proposto e validado por Santos e Cunha (2011), com o objetivo de identificar os conhecimentos explícitos dos alunos sobre os componentes estruturais de um texto narrativo. Em relação ao instrumento original, algumas alterações foram realizadas, a fim de adequá-lo ao gênero textual pesquisado, ou seja, histórias, tendo sido feita também a inclusão de solicitação de justificativas para as respostas.

\section{Procedimentos de coleta de dados}

A coleta de dados aconteceu em duas ocasiões. No primeiro dia os participantes foram convidados, em suas próprias salas de aula, a realizarem uma produção de texto (história), com temática livre. No dia seguinte, foram solicitados a responderem ao QAHM-H. Não houve restrição de limite de caracteres/linhas ou tempo para a realização das produções escritas. Já para a aplicação do QAHM-H, a pesquisadora lia um texto por vez e aguardava todos os alunos responderem as questões referentes ao mesmo.

\section{Procedimentos de análise dos dados}

O questionário foi composto por cinco pequenos textos de diferentes gêneros textuais e, para cada texto, o aluno deveria responder se o texto ouvido era ou não uma história (com opção de sim ou não) e escrever uma justificativa para a opção assinalada. Foi atribuído um ponto aos acertos nas questões fechadas (total de 5 pontos), bem como para as justificativas (total de 5 pontos), sendo que justificativas pouco elaboradas ou incompletas eram pontuadas com 0,5 ponto. O total de pontos possível nesse instrumento era, portanto, de 10 pontos.

As produções livres foram analisadas com base na categorização proposta nos trabalhos de Spinillo e Martins (1997); Oliveira et al., (2014). Assim, para o início (cenário) da história foram pontuados: presença de marco temporal (1 ponto); marco espacial (1 ponto) e; personagem(s) (com caracterização física ou psicológica, 1 ponto; se somente fosse citado, 0,5 ponto), total máximo de 3 pontos. Para o meio (trama) da história: narração de sequência de ações que configurassem um problema com bom nível de complexidade (3 pontos); desenvolvimento e situação problema pouco elaborados (2 pontos); apenas relato de fato(s) que pode $(\mathrm{m})$ ser considerado(s) problemático(s) ou esboço de um problema (1 ponto); ausência de desenvolvimento ou situação problema ( 0 pontos), total máximo de 3 pontos. Já para o final (desfecho) da história, foram considerados: resolução da situação problema e um fechamento, indicado por marcadores linguísticos como "... e foram felizes para sempre" (3 pontos); apenas solução da situação problema (2 pontos); fechamento abrupto sem resolução da situação problema (1 ponto); sem desfecho (0 pontos), total máximo de 3 pontos. Além disso, com base na coerência e coesão dos textos produzidos mais um ponto era atribuído (ou não). Dessa forma, foi analisada a capacidade de controlar as diferentes ideias expressas no texto, mantendo uma compatibilidade entre elas, bem como de articular as diferentes proposições e relações entre os eventos narrados. A pontuação final da produção textual podia somar, portanto, 10 pontos.

Para ambos os instrumentos (questionário e produção), as análises foram conduzidas por dois juízes independentes, tendo sido calculado o coeficiente de correlação intraclasse (CCI), obtendo um Coeficiente Alfa de Cronbach $(\alpha)$, acima de 0,9 o qual indica um excelente nível de concordância (Matos, 2014). Quando as pontuações diferiam entre os juízes, era utilizada a média aritmética das duas avaliações.

\section{Resultados}

Após a pontuação das produções livres e questionários por meio dos critérios elaborados, a análise dos dados foi conduzida no programa Statistical Package for the Social Sciences 20.0 (SPSS). A Tabela 1 apresenta os resultados da análise descritiva do desempenho dos participantes no QAHM-H e produção de texto, levando em conta tanto a amostra total quanto o grau escolar. Apresenta também os resultados (significância) do teste de normalidade de Shapiro-Wilk, indicando que os resultados obtidos no QAHM-H tendem a se afastar de uma distribuição normal, sugerindo a utilização de testes não paramétricos nas análises inferenciais que incluem essa variável. 
TABELA 1

Análise descritiva dos resultados obtidos pelos participantes nas avaliações efetuadas, de acordo com o grau de escolaridade

\begin{tabular}{|c|c|c|c|c|c|c|c|c|c|c|c|}
\hline & \multicolumn{6}{|c|}{ Questionário (QAHM-H) } & \multicolumn{5}{|c|}{ Produção de Texto } \\
\hline & $N$ & Med. & $D P$ & Min. & Max. & $\begin{array}{c}\text { Sig } \\
\text { (Shap.-Wilk) }\end{array}$ & Med. & $D P$ & Min. & $\operatorname{Max}$ & $\begin{array}{c}\text { Sig } \\
\text { (Shap.-Wilk) }\end{array}$ \\
\hline Amostra Total & 95 & 6,72 & 1,48 & 2,0 & 9,5 & $0,008 * * *$ & 6,21 & 1,78 & 1,5 & 10,0 & 0,401 \\
\hline 4 - Ano & 35 & 6,70 & 1,55 & 2,0 & 9,5 & $0,047^{*}$ & 5,51 & 1,71 & 1,5 & 8,5 & 0,224 \\
\hline 5o Ano & 60 & 6,72 & 1,45 & 3,0 & 9,0 & 0,065 & 6,61 & 1,70 & 2,0 & 10,0 & 0,497 \\
\hline
\end{tabular}

Nota: valores de $p<0,05^{*}$; valores de $p<0,01 * * *$.

TABELA 2

Resultados da Correlação de Spearman e correlação parcial (com controle do ano escolar) entre habilidades metatextuais e de produção textual

\begin{tabular}{|c|c|c|c|}
\hline & & & $\begin{array}{c}\text { Questionário } \\
\text { (QAHM-H) }\end{array}$ \\
\hline \multirow{3}{*}{ Correlação de Spearman } & \multirow{3}{*}{ Produção de Texto } & Coef. de correlação & $0,266^{* *}$ \\
\hline & & Sig. (bilateral) & 0,009 \\
\hline & & $\mathrm{N}$ & 95 \\
\hline \multirow{3}{*}{ Correlação parcial (ano escolar) } & \multirow{3}{*}{ Produção de Texto } & Coef. de correlação parcial & $0,315^{* *}$ \\
\hline & & Sig. (bilateral) & 0,002 \\
\hline & & $\mathrm{N}$ & 95 \\
\hline
\end{tabular}

Nota: Foram consideradas correlações fracas valores entre 0 e 0,39 , correlações moderadas valores entre 0,40 e 0,69 e correlações fortes valores entre 0,70 e 0,99 (Dancey \& Reidy, 2006).

Com o intuito de responder ao objetivo geral deste estudo, ou seja, verificar a relação entre habilidade metatextual (conhecimento sobre a estrutura narrativa) e o desempenho na produção escrita de histórias, utilizou-se o teste de correlação de Spearman. Na Tabela 2 são observados os resultados das análises de correlação entre as habilidades avaliadas para a amostra total $(r s=0,266)$, bem como o resultado da correlação parcial, controlando o nível de escolaridade $(r p=0,315)$. Observa-se que ambas as análises indicam correlação positiva fraca, porém significativa entre conhecimento sobre a estrutura narrativa e o desempenho na produção escrita de histórias.

Foi realizada também a análise comparativa do desempenho dos alunos do $4^{\mathrm{O}}$ e do $5^{\mathrm{O}}$ ano, tanto no que se refere às habilidades metatextuais (QAHM-H), quanto no que se refere à organização estrutural dos textos produzidos. Os resultados dessas análises encontram-se na Tabela $\mathbf{3}$, apresentada a seguir. Observa-se que, embora as produções de texto dos alunos do $5^{\mathrm{o}}$ ano tenham obtido média significativamente diferente (maior) do que a média dos alunos do 4음 ano, essa diferença não se manifestou quanto às habilidades metatextuais, ou seja, no que diz respeito ao conhecimento da estrutura do texto narrativo, não houve diferenças significativas entre os dois grupos de alunos.
TABELA 3

Resultados da comparação do desempenho dos alunos do 40 versus $5^{\circ}$ ano nas habilidades metatextuais (QAHM-H) e na produção de texto (histórias)

\begin{tabular}{lcc}
\hline & Teste $t$ & Prova de Mann-Whitney \\
Produção Textual & $t=-3,032$ & - \\
& $p=0,003 * *$ & $z=-0,078$ \\
QAHM-H & - & $p=0,938$ \\
\hline
\end{tabular}

\section{Discussão}

O objetivo geral do estudo foi investigar a correlação entre habilidades metatextuais relativas ao conhecimento da estrutura narrativa e o desempenho na produção escrita de histórias de alunos dos 4 e e 50 anos do Ensino Fundamental. Assim, ao analisar a estrutura narrativa das produções textuais e correlacionar esses resultados com a pontuação obtida na análise dos questionários, para avaliar os conhecimentos metatextuais dos participantes, observou-se que os resultados indicaram uma fraca correlação positiva entre as habilidades.

No estudo de Pereira (2010), analisando as relações entre habilidades metatextuais e produção de texto narrativo em crianças de $3 \stackrel{\circ}{\circ}, 4^{\circ}$ e $5^{\circ}$ anos, foram 
encontradas correlações mais fortes $(r=0,67)$ entre essas habilidades. É importante ressaltar, entretanto, algumas diferenças importantes entre as metodologias adotadas, uma vez que o referido estudo avaliou as competências metalinguísticas e de produção de texto oralmente e com uma amostra de crianças da classe média. Já a pesquisa de Lopes (2016), analisando a correlação entre consciência metatextual e resumo de histórias em alunos dos $5^{\mathrm{O}}$ e $6^{\mathrm{O}}$ anos do Ensino Fundamental, obteve correlação moderada $(\mathrm{r}=0,44)$ entre essas habilidades, aproximando-se mais dos resultados obtidos no presente estudo.

Foi observado também o efeito da série escolar no desempenho em produção textual, com os alunos do 5 o ano saindo-se significativamente melhor do que os alunos do $4 \mathrm{O}$ ano. Tais resultados confirmam os de outros estudos (Lins e Silva \& Spinillo, 1998; Pessoa, Correa, \& Spinillo, 2010) que apontam a escolaridade como um dos fatores determinantes do desempenho na escrita de textos. Chama a atenção, entretanto, o fato de não serem encontradas diferenças significativas entre as habilidades metatextuais dos alunos de 4 o e 5은 ano. Tais resultados sugerem que, mesmo possuindo relativamente os mesmos conhecimentos a respeito da estrutura do texto narrativo, estes não foram utilizados tão bem pelos alunos do 40 ano de modo a apoiar a redação de seus textos, os quais apresentaram mais problemas no que diz respeito à estrutura narrativa. Com efeito, foi observado, na comparação da análise das respostas dos questionários com os textos produzidos, que muitos dos argumentos apresentados pelos alunos nos questionários, para justificar se um texto era ou não uma história, não foram incorporados na sua produção escrita. Cita-se, como exemplo, alunos que respondiam no questionário que determinado texto era uma história porque apresentava começo, meio e final, mas na sua história não aparecia o meio.

Resultados similares foram encontrados na pesquisa de Pinheiro e Leitão (2007), que tinha como objetivo investigar em que medida a consciência que os indivíduos teriam dos elementos constituintes da estrutura prototípica da argumentação se relacionaria à tendência dos mesmos indivíduos incorporarem tais elementos nos textos que produzissem. Dessa forma, os resultados indicaram que os elementos considerados relevantes pelos participantes quando julgavam diferentes versões textuais, não eram necessariamente utilizados por eles na produção dos próprios textos.

Os resultados observados podem ser explicados pelos processos envolvidos no desenvolvimento dos conhecimentos metacognitivos, ou seja, como adquirem e fazem uso de estratégias metacognitivas que lhes possibilitem planejar e monitorar o seu desempenho (Ribeiro, 2003), o que favoreceria também o desenvolvimento das habilidades metatextuais. Assim, inicialmente os alunos apresentam alguns conhecimentos declarativos (Paris et al., 1983), relacionados às justificativas fornecidas nos questionários, ou seja, a descrição daquilo que se sabe. Já os conhecimentos cognitivo, executivo e condicional, relacionados ao controle e autorregulação da atividade cognitiva, ainda aparecem limitados, como sugere a análise das produções textuais, ou seja, falta-lhes maior domínio sobre como, quando e onde usar um conhecimento ou estratégia específica.

Percebe-se também, tanto pela pontuação média obtida nos questionários quanto nas produções de texto, que os alunos da amostra estudada ainda têm muito a evoluir, sendo seus conhecimentos metatextuais mais de ordem implícita do que explícita. De fato, embora eles consigam diferenciar uma história de outros tipos de texto, têm dificuldades em explicitar no que consistem essas diferenças e, sobretudo de aplicar esses conhecimentos em uma tarefa de produção textual. Como ressalta Gombert (1992; 2003; 2008), as habilidades propriamente metatextuais geralmente resultam de aprendizagens sistemáticas ocorridas em função de experiências de ensino explícito.

É importante levar em conta também que os alunos do ensino público tendem a levar mais tempo para se tornarem alfabetizados do que os alunos do ensino particular. Nesse sentido, é possível - e as várias questões ortográficas encontradas nos textos produzidos assim o indicam - que os participantes da pesquisa e, sobretudo os alunos do $4^{\circ}$ ano, ainda não tivessem superado questões básicas relativas ao domínio do sistema de escrita alfabético. Sendo assim é possível supor que os recursos cognitivos dessas crianças estivessem menos disponíveis, durante a atividade de produção de texto, para acessar processos metacognitivos de planejamento e autorregulação. Resultados obtidos com alunos portugueses (Limpo \& Alves, 2013) indicam as habilidades ortográficas (spelling) como um dos preditores mais importantes para a qualidade dos textos produzidos, associação essa também encontrada em estudos brasileiros (Nobile \& Barrera, 2016; Salles \& Correa, 2014).

Possivelmente, esses alunos necessitariam, por um lado, aprimorar suas habilidades básicas de escrita e, por outro, de maiores esclarecimentos e atividades que os levassem a identificar e refletir intencionalmente sobre as características do texto narrativo, de modo a poder usar esse conhecimento de forma mais eficiente nas situações de produção de texto. De fato, resultados positivos obtidos com a intervenção visando ao desenvolvimento das habilidades metatextuais 
sobre o desempenho em produção de texto têm sido encontrados em várias pesquisas (Oliveira et al., 2014; Pinheiro; 2012; Rodrigues \& Vilela, 2012; Spinillo \& Reis, 2018; Zaboroski et al., 2015).

\section{Considerações finais}

A análise realizada possibilitou visualizar que as habilidades metatextuais e de produção de textos narrativos de alunos de 4ㅇ e 5ㅇ anos do ensino público fundamental encontram-se positiva e significativamente correlacionadas. Observou-se, entretanto, que essas habilidades não são adequadamente utilizadas pelos participantes no momento da produção de texto propriamente dito, sobretudo no que se refere aos alunos do 4 o ano. Uma possível conclusão é de que os alunos desse ano ainda não estejam plenamente alfabetizados, o que possibilitaria aos mesmos alocarem seus recursos cognitivos para atividades mais complexas, relacionadas ao acesso dos conhecimentos e estratégias metacognitivas.

Em relação às habilidades metatextuais, esperase que os alunos, possam desenvolvê-las a partir de um ensino sistemático sobre a estrutura textual que possibilite ir além de conhecimentos implícitos, de modo a permitir maior controle sobre esses conhecimentos. Tal controle, também identificado na literatura sob o termo "autorregulação" pressupõe uma atividade intencional e reflexiva sobre os componentes estruturais do texto, bem como o domínio da coerência e coesão, os quais, associados aos conhecimentos sobre o conteúdo a ser abordado, contribuirão de forma efetiva tanto para o planejamento como para a organização e revisão dos textos a serem produzidos.

Como vários fatores estão ligados ao desenvolvimento das habilidades de produção de texto além das habilidades metatextuais (escolaridade, contato com diversos tipos de textos, competências ortográficas, situação de produção), compreende-se que a relação entre essas habilidades seja fraca. Por outro lado, enfatizar a importância das habilidades metatextuais na escrita de textos significa reforçar a importância que a escola assume com relação a essas competências, oferecendo e criando oportunidades de práticas educativas que levem o aluno a refletir deliberadamente sobre a estrutura dos diferentes tipos e gêneros textuais.

Uma limitação que pode ser apontada no presente estudo diz respeito ao fato de que a metodologia correlacional adotada não permite sustentar hipóteses de relação causal entre as variáveis estudadas. Sugere-se assim, que mais estudos se dediquem à investigação das habilidades metatextuais e de suas relações com o desempenho na escrita de textos, se possível fazendo uso de metodologias experimentais e utilizando também outros tipos de textos. Uma análise sistemática das habilidades de escrita (conhecimento ortográfico) também seria desejável, de modo a considerar a relação dessa competência com a produção de textos e as habilidades metatextuais.

\section{Referências}

Abaurre, M. B. M. (1997). (Re) escrevendo: o que muda? In M. B. M. Abaurre, R. S. Fiad \& M. L. T. MayrinkSabinson (Orgs.), Cenas de aquisição da escrita: o sujeito e o trabalho com o texto (pp. 61-69). Campinas, SP: Associação de Leitura do Brasil (ALB): Mercado das Letras. https://doi.org/10.20396/cel.v44i0.8637084

Barrera, S. D. \& Santos, M. J. dos. (2016). Produção escrita de narrativas: influência de condições de solicitação. Educar em Revista, 62, 69-85. https://doi.org/10.1590/0104-4060.48026

Brown, A. (1987). Metacognition, Executive control, self-regulation, and other more mysterious mechanisms. In F. E. Weinert \& R. H. Kluwe (Orgs.), Metacognition, motivation, and understanding (pp. 65-116). Hillsdale, NJ: Lawrence Erlbaum. (DOI INEXISTENTE)

Corso, H. V., Sperb, T. M., Jou, G. I. de, \& Salles, J. F. (2013). Metacognição e funções executivas: relações entre os conceitos e implicações para a aprendizagem. Psicologia: Teoria e Pesquisa, 29(1), 21-29. https://doi.org/10.1590/ s0102-37722013000100004

Dancey, C. P. \& Reidy, J. (2006). Statistics without Mathematics to Psychology: Using SPSS for Windows. Porto Alegre, RS: Artmed. (DOI INEXISTENTE)

Ferreira, A. L. \& Spinillo, A. G. (2003). Desenvolvendo a habilidade de produção de textos em crianças a partir da consciência metatextual. In M.R. Maluf (Org.), Metalinguagem e aquisição da escrita: contribuições da pesquisa para a prática da alfabetização (pp. 119-148). São Paulo, SP: Casa do Psicólogo. https://doi. org/10.11606/d.59.2018.tde-16072018-144040 
Ferreira, S. P. \& Correa, J. (2008). A influência de diferentes contextos de intervenção na escrita de histórias por crianças. Estudos de Psicologia, 25(4), 547-555. https://doi.org/10.1590/s0103-166x2008000400009

Flavell, J. (1987). Speculations about the nature and development of metacognition. In F. E. Weinert \& R. H. Kluwe (Orgs.), Metacognition, motivation, and understanding (pp. 21-29). Hillsdale, NJ: Lawrence Erlbaum. (DOI INEXISTENTE)

Flower, L. \& Hayes, J. R. (1981). A Cognitive Process Theory of Writing. College Composition and Communication, 32(4), 365-387. https://doi.org/10.2307/356600

Foulin, J. N. \& Mouchon, S. (2000). Psicologia da Educação. Porto Alegre, RS: Artmed.

Gombert, J. E. (1992). Metalinguistic development. Hertfordshire: Harvester Wheatsheaf. (DOI INEXISTENTE)

Gombert, J. E. (2003). Atividades metalinguísticas e aprendizagem da leitura. In M. R. Maluf (Org.), Metalinguagem e aquisição da escrita: contribuições da pesquisa para a prática da alfabetização (pp. 19-63). São Paulo, SP: Casa do Psicólogo. https://doi.org/10.11606/d.59.2018.tde-16072018-144040

Hodges, L. D. \& Nobre, A. P. (2012). Processos cognitivos, metacognitivos e metalinguísticos na aquisição da leitura e escrita. Revista Teoria e Prática da Educação, 15(3), 85-97. https://doi.org/10.0000/rtpe.v15i3.25490

Jou, G. I. de \& Sperb, T. M. (2006). A metacognição como estratégia reguladora da aprendizagem. Psicologia: Reflexão e Crítica, 19(2), 177-185. https://doi.org/10.1590/s0102-79722006000200003

Limpo, T. \& Alves, R. A. (2013). Modeling writing development: Contribution of transcription and self-regulation to Portuguese students' text generation quality. Journal of Educational Psychology, 105(2), 401-413. https://doi. org/10.1037/a0031391

Lins e Silva, M. E. \& Spinillo, A. G. (1998). Uma análise comparativa da escrita de histórias pelos alunos de escolas públicas e particulares. Revista Brasileira Estudos Pedagógicos, 193(79), 6-16. https://doi.org/10.24109/21766681.rbep.79i193

Lins e Silva, M. E. \& Spinillo, A. G. (2000). A influência de diferentes situações de produção na escrita de histórias. Psicologia: Reflexão e Crítica, 13(3), 337-350. https://doi.org/10.1590/s0102-79722000000300003

Lopes, M. M. (2016). Consciência Metatextual, compreensão leitora e resumo de histórias - possíveis relações em uma perspectiva psicolinguística. Signo, 41(71), 50-62. https://doi.org/10.17058/signo.v41i71.7195

Maluf, M. R. \& Gombert, J. E. (2008). Habilidades implícitas e controle cognitivo na aprendizagem da linguagem escrita. In M. R. Maluf \& S. R. K. Guimarães (Orgs.), Desenvolvimento da Linguagem Oral e Escrita (pp.123-135). Curitiba, PR: Editora UFPR. https://doi.org/10.11606/t.59.2016.tde-19012016-094005

Marcuschi, L. A. (2002). Gêneros textuais: definição e funcionalidade. In A. P. Dionisio, A. R. Machado \& M. A. Bezerra (Orgs.), Gêneros textuais \& Ensino (pp. 19-36). Rio de Janeiro, RJ: Lucerna. (DOI INEXISTENTE)

Matos, D. A. S. (2014). Confiabilidade e concordância entre juízes: aplicações na área educacional. Estudos em Avaliação Educacional, 25(59), 298-324. https://doi.org/10.18222/eae255920142750

Nobile, G. G. \& Barrera, S. D. (2016). Desempenho ortográfico e habilidades de produção textual em diferentes condições de solicitação. Psicologia: Teoria e Pesquisa, 32(2), 1-10. https://doi.org/10.1590/0102-3772e32226

Oliveira, J. P. de, Zaboroski, A. P., Mello, P. M., Semkiv, S. I A. L., \& Braga, T. M. S. (2014). O uso do texto narrativo em crianças que possuem atraso no processo de aquisição e desenvolvimento da linguagem escrita. In J. P de O., T. M. S. Braga, F. L. P. Viana, \& A. S. Santos (Orgs.), Alfabetização em países de língua portuguesa: pesquisa e intervenção (pp. 201-216). Curitiba, PR: Editora CRV. https://doi.org/10.24824/978858042522.2

Paris, S. G., Lipson, M. Y., \& Wixson, K. K. (1983). Becoming a strategic reader. Contemporary Educational Psychology, 8, 293-316. https://doi.org/10.1016/0361-476x(83)90018-8

Pereira, A. P. (2010). As relações entre consciência metatextual, produção e compreensão de textos (Dissertação de mestrado). Centro de Filosofia e Ciências Humanas, Universidade Federal de Pernambuco, Recife. https://doi. org/10.7202/500614ar

Pereira, L. Á. \& Barbeiro, L. F. (2010). A revisão textual acompanhada como estratégia de Ensino da produção escrita. In M. J. de M. Luna, A. G. Spinillo, \& S. G. Rodrigues (Orgs.), Leitura e produção de texto (pp. 51-80). Recife, PE: Editora Universitária da UFPE. https://doi.org/10.20873/uft.2179-3948.2018v9n2p341

Pessoa, A. P., Correa, J., \& Spinillo, A. G. (2010). Contexto de produção e o estabelecimento da coerência na escrita de histórias por crianças. Psicologia: Reflexão e Crítica, 23(2), 253-260. https://doi.org/10.1590/s010279722010000200007 
Pinheiro, L. R. (2012). A produção de textos de opinião como expressão da consciência metatextual: uma intervenção no contexto escolar (Tese de doutorado). Universidade Federal do Paraná, Curitiba. https://doi. org/10.1590/0104-4060.48310

Pinheiro, R. \& Leitão, S. (2007). Consciência da "Estrutura Argumentativa" e produção textual. Psicologia: Teoria e Pesquisa, 23(4), 423-432. https://doi.org/10.1590/s0102-37722007000400008

Rego, L. L. B. (1986). A escrita de estórias por crianças: as implicações pedagógicas do uso do registro lingüístico. Revista de Documentação de Estudos em Lingüística Teórica e Aplicada, 2(2), 165-180. https://doi. org/10.1590/0102-445042525725326599

Ribeiro, C. (2003). Metacognição: um apoio ao processo de aprendizagem. Psicologia: Reflexão e Crítica, 16(1), 109-116. https://doi.org/10.1590/s0102-79722003000100011

Rodrigues, M. R. F. \& Vilela, F. C. (2012). Resolução da situação-problema e desfecho em histórias de crianças de 7 e 9 anos. Psicologia: Ciência e Profissão, 32(2), 422-437. https://doi.org/10.1590/s1414-98932012000200011

Salles, J. F. de \& Correa, J. (2014). A produção escrita de histórias por crianças e sua relação com as habilidades de leitura e escrita de palavras/pseudopalavras. Psicologia USP, 25(2), 189-200. https://doi.org/10.1590/0103$6564 \mathrm{a} 20133813$

Santos, M. J. dos \& Barrera, S. D. (2015). Escrita de textos narrativos sob diferentes condições de produção. Psicologia Escolar e Educacional, 19(2), 253-260. https://doi.org/10.1590/2175-3539/2015/0192827

Santos, A. A. A. \& Cunha, N. B. C. (2011). Consciência metatextual: evidências de validade para instrumento de medida. Psico-USF, 17(2), 233-241. https://doi.org/10.1590/s1413-82712012000200007

Silva, T. F. da \& Guimarães, S. R. K. (2017). Habilidades metatextuais: revendo evidências de pesquisas brasileiras. In M. R. Maluf \& M. J. dos Santos (Orgs.), Ensinar a ler: das primeiras letras à leitura fluente (pp. 117-144). Curitiba, PR: CRV. https://doi.org/10.24824/978854441527.6

Spinillo, A. G. \& Martins, R. A. (1997). Uma análise da produção de histórias coerentes por crianças. Psicologia: Reflexão e Crítica, 10(2), 219-248. https://doi.org/10.1590/s0102-79721997000200004

Spinillo, A. G. \& Correra, J. (2016). A revisão textual na perspectiva de professores do ensino fundamental. Educar em Revista, 62, 107-123. https://doi.org/10.1590/0104-4060.48024

Spinillo, A. G. \& Melo, K. L. R. (2018). O papel do conhecimento acerca da estrutura do texto na escrita de histórias por crianças. Educar em Revista, 34(69), 277-292. https://doi.org/10.1590/0104-4060.54654

Zaboroski, A. P., Antozczyszen, S., Michelon, L. J., \& Oliveira, J. P. de (2015). Desempenho de escolares em produções escritas antes e após uma proposta de intervenção interdisciplinar. Distúrbios da Comunicação, 27(3), 544-557. https://doi.org/10.31692/2358-9728.iiicointerpdvl.2016.00068

\footnotetext{
Dados dos autores:

Endereço para correspondência:

Gislaine Gasparin Nobile

Fazenda Sede São Manoel, s/n. - Bonfim Paulista

14110-000, São Paulo, SP, Brasil

E-mail: gislainenobile@yahoo.com.br

Recebido em: 06/02/2018

Aceito em: 12/09/2018.

Publicado em: 05/08/2019.
}

Gislaine Gasparin Nobile - Doutora, Universidade de São Paulo.

Sylvia Domingos Barrera - Pós-Doutorado, Universidade de São Paulo. 